\section{Time for Elitism}

A cONGRESS of barbers, gathered to hear the latest about hairdressing techniques and told by their president that in the past thirty years the quality of their work had declined, that they were taking too long to cut customers' hair and that they overcharged the public, would undoubtedly be in a lynching mood. The barbers, exposed for what they were, on returning to their shops would find an angry public demanding refunds. For this reason, if no other, senior members of trades and professions are not given to criticizing their colleagues in public--except, that is, for Professor Kenneth Mellanby.

At the annual meeting of the British Association this year Professor Mellanby, President of Section X and Director of the Nature Conservancy Monks Wood Experimental Station, announced that science was overstaffed and mismanaged. He said that although funding has multiplied a hundred-fold since the 1930s "productivity", however determined, has declined sadly. More money has meant more jobs, and the larger the "team", the less the creative mind around which this structure is developed can do anything but administrate. The only corrective Professor Mellanby sees is an unashamedly elitist approach-support the good and do not allow the less than good to pretend they are doing constructive research.

Two issues need discussion. One is simply whether Mellanby is making a correct judgment. The other is that if he is indeed right, why does not a statement like this raise more than a ripple?

The theme that science is not what it used to be is not a new one. As long ago as 1830, Charles Babbage could write a book persuasively and wittily on unfavourable trends, including expansionism, among scientists. $\mathrm{He}$ would have had no difficulty in revising it for the 1970s. The present day problem seems to be a lack of incisiveness among scientists in converting personal opinions into action. Although it is indisputable that the contributions of some scientists are consistently brilliant and the contributions of others are consistently negligible, the processes of natural selection are seriously impaired by some form of gentlemen's agreement which classifies open criticism of the mediocre as intolerable rudeness. The process starts early when failure to get a PhD is seen as such a humiliation both for student and adviser that the standards of the degree are seriously depressed to accommodate students who are not natural research workers.

The fault is not the student's because no one has had the courage to say "you are not going to make the grade". Then, armed with a certificate to do research, most will settle for nothing less, and none will say nay because who can tell what someone might come up with?

This is a serious misreading of the character of observational science. No one visiting Cambridge should fail to observe Eric Gill's stone inscription on the Department of Zoology Dans les champs de l'observation, le hasard ne favorise que les espirits préparés: scientists of distinction lead a favoured life, not because they are lucky but because they know how to capitalize on their luck. To encourage those to stay in the field who clearly lack the ability out of a hope that something may turn up is often no more profitable than providing monkeys with typewriters because they might turn out a work of genius.

The overpopulated ranks of research are not, however, merely an expensive phenomenon. They do, as Mellanby points out, constrict, if not throttle, the creativity of the bright who frequently lack the political skill or authority to thin out teams of research workers willed on them. The administrative load can be crippling, of course, although it is frequently self-imposed, but there is also the intellectual load of devising thesis topics and trying to keep employees abreast of original research.

All this suggests considerable reduction in the ranks of those who call themselves researchers. It is not easy to suggest means of doing this which do not hurt, but in trying to give an answer to the question "Why a mere ripple from this statement?", the urgency of finding an answer may at least be underlined.

Until now there has been little feeling amongst scientists that they are living largely off taxpayers' money (many industrial scientists included), nor does the taxpayer readily associate criticism of scientific research with his tax bill. Yet the amount that he pays in Britain for the research council (a modest fraction of the total research and development expenditure) is at least as much as he pays each year for having his hair cut. Awareness of this (perhaps not in such specific terms) cannot but increasethe Apollo space programme, if it did nothing else for the man in the street in the United States, gave him an insight into the relationship between taxes and research spending.

It is arguable that Britain is beginning to become a post-industrial society. If so, science will not occupy the revered position it has for the past hundred years and we will hear more of the market-place approach to expenditure on research-if composers, printers, poets and sportsmen have to survive on the quality of what they provide, should research scientists be exempt?

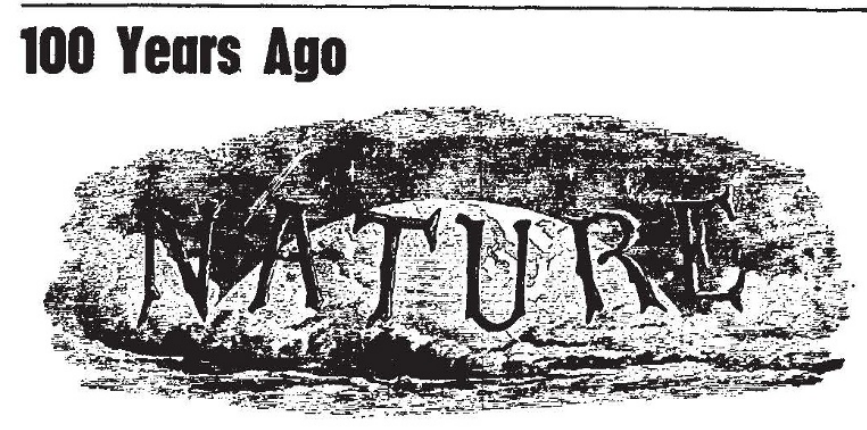

AMONG Messrs. [Macmillan's announcements of 'forthcoming works are-" OOn the Theory of Sound," by Lord Rayleigh, F.R.S. ; "Contributions to Solar Physics," by J.Norman Lockyer, F.R.S., with numerous illustrations; "Cave Hunting," by W. Boyd Dawkins, F.R.S., being researches on the evidence of caves respecting the early inhabitants of Europe ; "The Origin and Metamorphoses of Insects," by Sir John Lubbock, F.K.S. (vol. ii. NATURE Series); land a new edition of Canon Kingsley's "Glaucus."

From Nature 8, 390, September 11, 1873 


\section{Sakharov Taken to Task in Pravda}

IN July Dr Andrei Sakharov, the Soviet nuclear physicist, gave a widely publicized interview to Swedish television. He vigorously attacked a system perpetuating criminality and privilege and pointed to favoured treatment that was afforded to Communist Party members in medical care. The Academician also denounced lack of freedom both in ideas and travel. The literature, he said, is "grey, official, solemn and boring"; travel is restricted both within the Soviet Union and beyond so that Soviet society is divided by visa constraints and Soviets are not afforded sufficient opportunities to leave the country and return.

Since then Dr Sakharov has been warned by the Deputy General Procurator about his civil rights activities, and in particular this interview. He says that he was told the Procuracy could no longer stand aside, as these activities were providing information of interest to foreign intelligence services.

In the past few days several letters have been published in Pravda concerning Sakharov's activities-from, amongst others, members of the Academy of Agricultural Sciences, the Ukranian Academy of Sciences, the Siberian branch of the Academy of Sciences and a lathe operator in Leningrad. We reprint translations of two of the most interesting letters, from members of the Soviet Academy of Sciences and from a group of distinguished Soviet composers.

WE feel it necessary to bring to the attention of a wide public our attitude to the behaviour of Academician A. D. Sakharov.

In recent years, Academician Sakharov has turned away from active scientific work and has come out with a number of statements discrediting the state system and the external and internal policies of the Soviet Union. Recently, in an interview to foreign correspondents in Moscow which was published in the Western press, he reached the stage where he came out against the policy of the Soviet Union of relieving international tension and of consolidating those positive changes which have taken place recently throughout the world.

These statements, which are completely alien to the interests of all progressive peoples, Sakharov tries to justify by crude distortions of Soviet activity and imaginary reproaches regarding the socialist system. In his dicta he in effect takes up a position of solidarity with the most reactionary imperialist circles, coming out actively against the course of the peaceful coexistence of countries with different social systems, against our party and state attitudes to the development of scientific and cultural cooperation and to the strengthening of peace between nations. Thus Sakharov has become a weapon of hostile propaganda against the Soviet Union and other socialist countries.

The activity of Sakharov is at its roots alien to Soviet science. It looks especially unattractive against the background of the concentration of the efforts of our whole people on the solution of the weighty problems of economic and cultural construction of the USSR, on the strengthening of peace and on the protection of the health of the international situation.

We wish to express our indignation at the statements of Academician A. D. Sakharov and resolutely condemn his activity, which is a discredit to the honour and dignity of a Soviet scientist. We hope that Academician Sakharov will think over his activities.

Signed by Academicians:

N. G. Basov
N. V. Bolov

N. N. Bogolyubov

A. E. Braunshtein

A. P. Vinogradov

S. V. Vonsovskii

B. M. Bul

N. P. Dubinin

N. M. Zhavoro

B. M. Kedrov

M. V. Keldysh

V. A. Kotel'nikov

G. V. Kurdyumov

A. A. Logunov

(From Pravda, August 29, 1973)
HAVING familiarized ourselves with the letter of the members of the Academy of Sciences of the USSR, published in Pravda on August 29 , we, Soviet composers and musicians, entirely agree with their estimate of the activities of A. D. Sakharov, directed against the policy of the Soviet Union on relieving international tension, and his libellous statements regarding socialist reality. It is no coincidence that the reactionary Western press rapturously seizes on these antiSoviet "revelations".

We feel profound indignation at the actions of A. D. Sakharov, which are incompatible with the lofty title of Soviet citizen and public figure in Soviet science. His publications in the Western press are a disgrace to the honour and dignity of the Soviet intelligentsia (all the thoughts and aspirations of which are always continuously connected with the building of a new society) and the fight of the Soviet people for peace and for the extension of scientific and cultural cooperation with all countries.

Among us, representatives of Soviet art who are ever faithful to the high humanist ideals of rapprochement and mutual cooperation between nations and who unanimously support the policy of our Communist Party, the behaviour of A. D. Sakharov evokes a feeling of indignation and angry condemnation. Signed by:

D. Kabalevskii
K. Karaev
P. Savintsev
G. Sviridov
S. Tulikov
A. Khachaturyan

A. Kholminov T. Khrennikov D. Shostakovich R. Shchedrin

A. Eshpai

B. Yarutovskii.

(From Piavda, September 3, 1973)

D. V. Skobel'tsyn

S. L. Sobolev

V. I. Spitsyn

V. D. Timakov

A. N. Tikhonov

V. M. Tuchkevich

P. N. Fedossev

I. M. Frank

A. N. Frumkin

Yu. B. Khariton

M. V. Khrapchenko

P. A. Cherenkov

V. A. Engel'gardt
As Nature was going to press, news came of the first public defence of Sakhorov by anyone associated with the Soviet Academy. Mr Igor Shafarevich, an algebraist and a corresponding member of the Academy, issued an open letter in which he praised the conscience of a man who could speak out against the "vices and sores" of Soviet society. 